\title{
Successful control of bleeding from gastric antral vascular ectasia (watermelon stomach) by laser photocoagulation
}

\author{
H H Tsai, J Smith, B J Danesh
}

\begin{abstract}
We report a case of gastric antral vascular ectasia in a patient with primary biliary cirrhosis in whom chronic blood loss was a major problem. She required repeated blood transfusions that were complicated by reactions and still had persistent anaemia. She was treated with laser phototherapy in the form of quadrantic photocoagulation with a neodynium yttrium-aluminium-garnet laser. This greatly improved the endoscopic appearance of the gastric lesions and effectively controlled blood loss. She required no further transfusions. Bleeding recurred after 11 months which was controlled by further laser photocoagulation.
\end{abstract}

Gastric antral vascular ectasias were described in detail by Jabbari et $a l,{ }^{1}$ who also coined the term 'watermelon stomach' from its resemblance to the skin of a ripe watermelon on endoscopy. The condition, however, had been previously described. ${ }^{23}$ It is often misdiagnosed as antral gastritis or haemorrhage gastritis. ${ }^{4}$ It is now generally regarded as a distinct entity with typical endoscopic appearances and histological features. It often occurs in patients with liver diseases, particularly those with portal hypertension, and in patients with renal failure ${ }^{5-7}$ and pernicious anaemia. ${ }^{3}$ It commonly bleeds and may present as chronic anaemia. This is often difficult to control and may necessitate antrectomy. We report the successful use of laser photocoagulation in the control of haemorrhage in a patient with antral vascular ectasia.

\section{Case report}

A 42 year old woman in whom primary biliary cirrhosis was diagnosed in 1975 developed a mild anaemia for the first time in June 1986. This was attributed to her menorrhagia and the anaemia responded initially to treatment with oral iron. In February 1987 she was admitted because of a profound iron deficiency anaemia with a haemoglobin concentration of $60 \mathrm{~g} / \mathrm{l}$, and by this time she had ascites and splenomegaly. She had a serum ferritin concentration of $8 \mathrm{ng} / \mathrm{ml}$ (normal 14-130 $\mathrm{ng} / \mathrm{ml}$ ) and positive faecal occult blood. Upper gastrointestinal endoscopy showed oesophageal varices but with no stigmata of recent haemorrhage. It was also noted that she had antral lesions which were described as 'antral erosions'. She had also become amenorrhoeic with a negative pregnancy test.

It was initially assumed that she had bled from leaking varices and a course of sclerotherapy with ethanolamine was given. This virtually obliterated the oesophageal varices. Repeat endoscopy was carried out by a more experienced operator who correctly recognised the antral lesions as vascular ectasia (watermelon stomach). They had the typical features of bright red stripes radiating from the pylorus on the apices of mucosal folds and also had satellites of red spots. Biopsy specimens were taken from these lesions which bled easily. Histology of the specimens showed a mild reactive hyperplasia of the mucosa with some fibrosis and mild focal active gastritis. Most striking, however, were the appearances of ectatic irregular capillaries in the lamina propria with the occasional thrombosed vessel. These features are diagnostic of gastric antral vascular ectasia.

Over subsequent months she continued to bleed and required transfusions of an average of 3.4 units of blood a month which she received in three to four weekly intervals. A chromium-51 labelled red cell scintiscan localised the bleeding to the area around the gastric antrum. Faecal blood estimation gave a daily blood loss of $197 \mathrm{ml}$ (normal $<10 \mathrm{ml} /$ day). Previous reports ${ }^{18}$ suggested that this condition is unlikely to remit spontaneously and often requires antrectomy. Laparotomy, however, was best avoided in this patient as portal hypertension increased her risk and abdominal surgery would complicate a future liver transplant should this be necessary. It was decided to manage her conservatively initially.

She was thus started on ranitidine $150 \mathrm{mg}$ twice a day and sucralfate $1 \mathrm{~g}$ four times a day to try to reduce the damaging effects of acid and provide some protection to the mucosa. The endoscopic appearance of the antrum was assessed monthly and her blood count checked weekly. From July 1987 to June 1988 she was maintained on this treatment along with oral iron. There was, however, no improvement in the endoscopic appearances and her blood transfusion requirements did not change (Figure). In June 1988 laser treatment was started. Photocoagulation was carried out using the neodynium yttrium-aluminium-garnet (Nd:YAG) laser (Fiberlase 100, Pilkington). A quadrant of the affected area was treated at each session. The power setting for photocoagulation averaged $40 \mathrm{~W}$ and the pulses were delivered at a duration of 0.5 seconds. She required six sessions. These were separated by intervals of three to four weeks. There were no complications as a result of laser treatment. Endoscopic appearances after laser treatment showed marked improvement. Lesions, however, remained in the pyloric channel which was technically more difficult to treat. With the start of photocoagulation she 
Haemoglobin concentration before and during laser treatment.

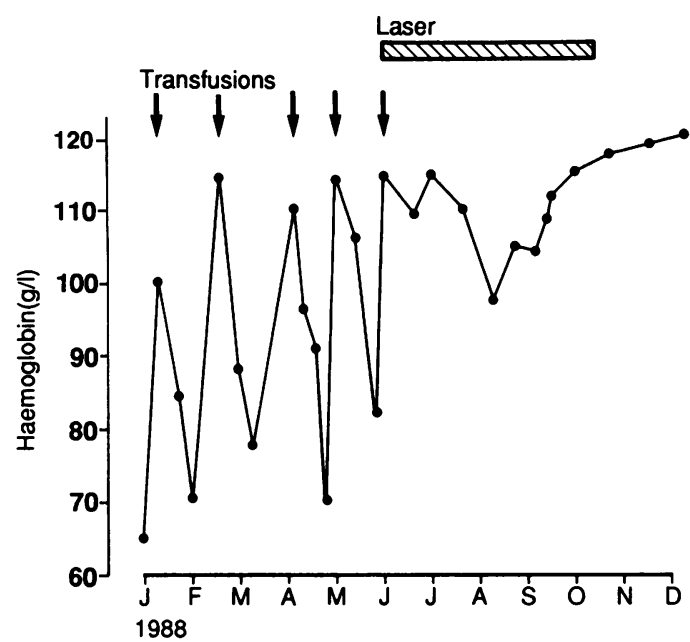

required no further blood transfusions. After an initial small fall in her haemoglobin concentration, it recovered to steady levels on oral iron only (Figure). Her serum ferritin rose to $37 \mathrm{ng} /$ $\mathrm{ml}$ and faecal occult blood became negative. She also reported a great improvement in her general well being and was able to return to normal activity and full employment.

She maintained her haemoglobin concentration until May 1989 when she had another episode of bleeding. Endoscopy showed recurrence of the vascular ectasia and no evidence of variceal bleeding. A further course of laser photocoagulation was given with similar satisfactory results.

\section{Discussion}

Antral vascular ectasia or 'watermelon stomach' is an uncommon condition. Control of blood loss is a major problem in this condition. The treatment of this condition is often unsatisfactory. Steroids have been reported to be of value, ${ }^{3}$ but there does not seem to be a rationale for its use. The number of reported cases of this condition is small, which may be due in part to its being frequently misdiagnosed, as was the case with this patient initially. In most reported cases control of haemorrhage was only achieved by antrectomy with a Billroth I reconstruction.

The aetiology of this condition remains obscure. It has been shown to be related to hypogastrinaemia and a low serum level of pepsinogen $I .^{8}$ Its association with liver disease perhaps suggests a role for hormonal abnormalities and portal hypertension. ${ }^{9}$ The role of acid and mucosal defence mechanisms remains unknown, but we have found the use of $\mathrm{H}_{2}$ antagonists and sucralfate disappointing in this patient. The presence of portal hypertension complicated the clinical picture somewhat. Portal hypertension is associated with oesophageal and gastric varices as well as an increased incidence of gastric erosions. This patient did not have gastric erosions or varices but did have oesophageal varices. Successful obliteration of these varices by sclerotherapy, however, did not alleviate her blood loss, making it likely that the haemorrhage arose from the vascular ectasia.

Lasers have been in use for treating upper gastrointestinal haemorrhage since $1976^{10}$ and found effective in controlling acute upper gastrointestinal bleeding from peptic ulcer disease in controlled studies. ${ }^{11-13}$ The Nd:YAG laser has also been used in the treatment of vascular abnormalities of both hereditary conditions (Osler-Rendu-Weber, blue rubber bleb naevus and Klippel-Trenauney syndromes) and acquired lesions associated with aortic valve, renal, and hepatic disease. ${ }^{14}$ While this report was being prepared, Gostout et al pubished a series of 13 patients with similar gastric lesions with satisfactory outcome in $12 .{ }^{15}$ Their patients, however, did not seem to have histological evidence of gastric antral vascular ectasia, diagnosis being made on endoscopic appearances only.

This report illustrates the successful use of laser in the control of blood loss in a patient with well documented evidence of gastric antral vascular ectasia associated with primary biliary cirrhosis. Laser photocoagulation is likely to be a safe, non-invasive, and effective means of treating this condition especially in patients with hepatic disease where surgery carries an increased risk.

1 Jabbari M, Cherry R, Lough JO, Daly DS, Kinnear DG, Goresky CA. Gastric antral vascular ectasia: the water-melon Goresky CA. Gastric antral vascular ectasia: the

2 Wheeler MH, Smith PM, Cotton PB, Evans DMD, Lawrie $\mathrm{BW}$. Abnormal blood vessels in the gastric antrum: a cause of upper gastrointestinal bleeding. Dig Dis Sci 1979; 24: 155-8.

3 Calam J, Walker RJ. Antral vascular lesion, achlorhydria and chronic gastrointestinal blood loss: response to steroids. Dig Dis Sci 1980; 25: 236-9.

4 Rector WG, Reynolds TB. Risk factors for haemorrhage from esophageal varices and acute gastric erosions. Gastroenterology 1985; 14: 139-53.

5 Zuckerman GR, Cornette GL, Clouse RE, Hartel HR. Upper gastrointestinal bleeding in patients with chronic renal failure. Ann Intern Med 1985; 102: 588-92.

6 Dave P, Romeu J, Antonelli A, Eiser R. Gastrointestinal telangiectasia: a source of bleeding in patients receiving telangiectasia: a source of bleeding in patients

7 Cunningham JT. Gastric telangiectasias in chronic hemodialysis patients: a report of six cases. Gastroenterology 1981; 81 1131-3.

8 Quintero E, Pique JM, Bombi kJA, et al. Gastric mucosal vascular ectasias causing bleeding in cirrhosis. Gastroenterology 1987; 93: 1054-61.

9 Sarfeh IJ, Tarnawski A. Gastric mucosal vasculopathy in portal hypertension. Gastroenterology 1987; 93: 1129-30.

10 Dwyer RM, Yellis AE, Craig J. Gastric hemostasis by laser phototherapy in man. $7 A M A$ 1976; 236: 1383-4.

11 McLeod IA, Mills PR, MacKenzie JE, Joffe SN, Russell RI, Carter DC. Neodynium yttrium aluminium garnet laser photocoagulation for major haemorrhage from peptic ulcers photocoagulation for major haemorrhage from peptic ulcers
and single vessels. A single blind controlled study. $\mathrm{Br} \mathrm{Med} \mathcal{F}$ and single vessels.

12 Rutgeerts P, Vantrappen G, Broeckeart L, et al. Controlled trial of YAG laser treatment of upper digestive hemorrhage. Gastroenterology 1982; 83: 345-8.

13 Swain CP, Kirkham JS, Salmon PR, Broom SG, Northfield TC. Controlled trial of Nd-YAG laser photocoagulation in bleeding pepric ulcers. Lancet 1986; i: 1113-6.

14 Rutgeerts P, van Gompel F, Greboes K, Vantrappen G, Rroeckaerts L, Coremans G. Long term results of treatment
Brots Broeckaerts $\mathrm{L}$, Coremans $\mathrm{G}$. Long term results of treatment
of vascular malformations of the gastrointestinal tract by of vascular malformations of the gastrointestinal tract by
neodynium YAG laser photocoagulation. Gut 1985; 26: 586neody.

15 Gostout CJ, Ahlquist DA, Radford CM, et al. Endoscopic laser therapy for watermelon stomach. Gastroenterology 1989; 96 1462-5. 